\title{
Predictors of Patient Satisfaction With Inpatient Hospital Pain Management Across the United States: A National Study
}

\author{
Daniel C. McFarland, DO ${ }^{\star *}$, Megan Johnson Shen, $\mathrm{PhD}^{2}$, Randall F. Holcombe, MD
}

\begin{abstract}
${ }^{1}$ Division of Network Medicine Services, Memorial Sloan Kettering Cancer Center Hematology/Oncology, West Harrison, New York; ${ }^{2}$ Center for Research on End of Life Care, Weill Cornell Medicine, New York, New York; ${ }^{3}$ Tisch Cancer Institute, Icahn School of Medicine at Mount Sinai, New York, New York.
\end{abstract}

Satisfactory pain management of hospitalized patients remains a national unmet need for the United States. Although prior research indicates that inpatient pain management may be improving nationally, not all populations of patients rate pain management as equally satisfactory. County-level predictors, such as demographics and population density, and hospital-level predictors (eg, hospitalbed number), are understudied determinants of pain management patient satisfaction. We created a multivariate regression model of pain management patient satisfaction scores as indicated by Hospital Consumer Assessment of
Healthcare Providers and Systems (HCAHPS) survey results based on county and hospital level predictors. Number of hospital beds $(\beta=-0.16)$, percent foreign-born $(\beta=$ $-0.16)$, and population density $(\beta=-0.08)$ most strongly predicted unfavorable ratings, whereas African American ( $\beta$ $=0.23)$, white $(\beta=0.23)$, and younger population $(\beta=0.08)$ most strongly predicted favorable ratings. Greater attention should be placed on pain management in larger hospitals that serve foreign-born patients in population-dense areas. Journal of Hospital Medicine 2016;11:498-501. (C) 2016 Society of Hospital Medicine
Pain management is an integral component of patientcentered medical care and is a major concern for patients who are hospitalized. ${ }^{1}$ Patient-reported ratings of pain management are highly correlated with overall satisfaction with healthcare delivery. ${ }^{2}$ Current research indicates that patient satisfaction with pain management may be improving ${ }^{3}$; however, there may be structural and county-level disparities in these improvements in satisfaction. Although patient satisfaction with pain management increased from 2008 to 2012, a discrepancy in patient satisfaction with pain management has emerged between 3 different hospital systems (safety net, acute care, critical access hospitals) ${ }^{3}$ Specifically, acute care hospitals provide less satisfactory pain management as compared to critical access hospitals. ${ }^{3}$ Although patients' perception of pain management is an integral part of delivering patient-centered care, prior research indicates that there may not be a simple inverse association between pain intensity score and patient satisfaction. ${ }^{4}$ The management of pain in hospitals continues to be problematic, perhaps, for instance, due to discrepancies in understanding the relationship between patient satisfaction and pain management. Certainly for this reason and many others, satisfaction with pain management is now one of the dimensions

\footnotetext{
*Address for correspondence and reprint requests: Daniel McFarland, DO, Division of Network Medicine Services, Memorial Sloan Kettering Cancer Center, 500 Westchester Ave., West Harrison, NY 10604; Telephone: 914-367-7294; Fax: 646-227-7283; E-mail: mcfarld1@mskcc.org

Additional Supporting Information may be found in the online version of this article.

Received: December 5, 2015; Revised: February 2, 2016; Accepted: February 14, 2016

2016 Society of Hospital Medicine DOI 10.1002/jhm.2576

Published online in Wiley Online Library (Wileyonlinelibrary.com).
}

assessed by the Hospital Consumer Assessment of Healthcare Providers and Systems (HCAHPS) survey, which is a global measure of patient satisfaction.

The HCAHPS survey is utilized by $85 \%$ of all USbased hospitals and gathers patient satisfaction information pertaining to 10 dimensions, including pain management. Patient satisfaction scores (via HCAHPS) now constitute $30 \%$ of Hospital Value-Based Purchasing (HVBP), which makes up $2 \%$ of at-risk reimbursements by the Centers for Medicare and Medicaid Services (CMS) as put forth by the Affordable Care Act (ACA) of 2010.5 The ACA mandates that payments to hospitals must partly depend on metrics that assess patient satisfaction, as broadly measured by the HCAHPS, which are completed by patients upon hospital discharge. ${ }^{5,6}$ Therefore, patient satisfaction, as measured by patients, now directly affects CMS payments for over 3000 hospitals across the United States. This constitutes a large amount of money for most hospitals that operate on high revenue but have low profit margins. As such, the $2 \%$ at-risk reimbursement may place many hospitals at financial risk that could be ameliorated with effective inpatient pain management.

In addition to its critical role in reimbursement to hospitals, patient satisfaction with pain management is also integrally related to providing patient-centered care. As such, patient satisfaction with pain management is considered a critical element of various models of the patient-centered approach to providing medical care. Although a medical inpatient team can assess objective signs of pain, patient-centric pain measurements are paramount in understanding the pain experience of patients and providing adequate pain management care. Moreover, patients, doctors, payers of medical services, and now CMS increasingly 
TABLE 1. Bivariate Linear Regression of Pain Management Patient Satisfaction With 20 Explanatory Variables (County-Level Demographics and Hospital Bed Numbers)

\begin{tabular}{lccc}
\hline Variable & Median Value (SD) & Regression \\
Coefficient (SE)
\end{tabular}

NOTE: Pain management patient satisfaction was determined by the percentage of patients who stated that their pain was "always" well controlled (median $71 \%$, SD 5.5 , range 33\%-100\%). Abbreviations: SD, standard deviation; $S E$, standard error. ${ }^{*} P<0.001 \ldots . . P<0.01$.

regard a patient-centered approach to medical care as crucial for the delivery of high-quality care.

HCAHPS survey sampling represents an excellent opportunity to help assess current gaps in patientcentered clinical care. However, "ecological" factors, such as county-level demographics and hospital size (eg, bed number), are known to influence health outcomes but have not been adequately studied in pain management patient satisfaction. ${ }^{7}$ Hospital and county-level factors may influence the degree to which patients experience patient-centered pain management care. For instance, most patient satisfaction scores are worse in urban areas. ${ }^{8,9}$ These disparities in patient satisfaction scores could be associated with population density, greater ethnic diversity or non-Englishspeaking individuals, or number of hospital beds.

The US Census demographics and hospital-bed number provide a concurrent measure that can be used across the country to estimate hospital ecology. This study evaluated the influence of county-level demographic and structural factors (ie, hospital beds) on patient satisfaction with hospital pain management in all HCAHPS-participating hospitals across the United States. We hypothesized that demographic diversity, higher population density, and higher numbers of hospital beds would predict lower levels of patient satisfaction with inpatient pain management.

\section{METHODS}

\section{Data Collection: County-Level Predictors}

Publically available data were obtained from the American Hospital Directory ${ }^{10}$ and United States
Census Bureau ${ }^{11}$ websites. Twenty US Census data categories were selected a priori by their clinical relevance to influence pain management perception out of the 50 publically reported US Census categories. Final variables utilized in regression modeling are listed under the Variable column in Table 1. Covariate correlation coefficients were all under 0.7 , indicating a lack of significant colinearity.

\section{Data Collection: Patient Satisfaction With Pain Management}

Pain management was measured using the HCAHPS survey pain management dimension by calculating the percentage of patient responders who said their pain was "always" controlled. HCAHPS data are publically available on the CMS Hospital Compare website. $^{6}$ It contains 32 questions that comprise 10 evaluative measures. It is provided to a random sample of patients across the United States throughout the year at 48 hours to 6 weeks after discharge from the hospital.

\section{Analytic Plan}

HCAHPS and US Census datasets were analyzed to assess their distribution curves. The population density variable was converted to a logarithmic scale to account for its skewed distribution and long tail in the area of low population density. Data were subsequently merged into an Excel (Microsoft Corp., Redmond, WA) spreadsheet using the VLOOKUP function such that relevant 2010 census county data were added to each hospital's HCAHPS data. 
TABLE 2. Multivariate Regression Predicting Patient Satisfaction With Pain Management From HCAHPS Scores According to County Demographics and Hospital Size

\begin{tabular}{|c|c|c|c|c|c|}
\hline Variable & Median Value (SD) & Range & Regression Coefficient (SE) & $\beta$ & $t$ Value \\
\hline African American alone, \% & $5.6 \%(13.8 \%)$ & $0 \%-85.4 \%$ & $0.07(0.01)$ & 0.23 & $7.104^{*}$ \\
\hline White alone, $\%$ & $86.2 \%(15.8 \%)$ & $5.3 \%-99.0 \%$ & $0.08(0.01)$ & 0.23 & $6.953^{*}$ \\
\hline Per capita income & $\$ 24,499(\$ 6,419)$ & $\$ 7,887-\$ 61,290$ & $0.00(0.00)$ & 0.22 & 2.885 \\
\hline With bachelor's degree, \% & $22.0 \%(10.1 \%)$ & $6.3 \%-70.7 \%$ & $0.03(0.02)$ & 0.10 & 1.401 \\
\hline Population < 18 years old, \% & $23.2 \%(3.1 \%)$ & $8.3 \%-40.6 \%$ & $0.18(0.05)$ & 0.08 & $3.498^{*}$ \\
\hline With a high school degree, \% & $86.0 \%(6.4 \%)$ & $46.3 \%-98.6 \%$ & $0.02(0.01)$ & 0.02 & 1.424 \\
\hline Population change over 1 year, \% & $0.7 \%(2.2 \%)$ & $-18.1 \%-25.6 \%$ & $-0.11(0.06)$ & -0.01 & -1.986 \\
\hline Same house over 1 year, $\%$ & $85.4 \%(4.2 \%)$ & $57.1 \%-98.0 \%$ & $-0.01(0.02)$ & -0.01 & -0.493 \\
\hline White alone (not Hispanic), \% & $75.2 \%(21.8 \%)$ & $3.2 \%-98.4 \%$ & $-0.02(0.00)$ & -0.01 & -0.740 \\
\hline Household size & $2.52(0.3)$ & $1.92-4.77$ & $-0.92(0.80)$ & -0.03 & -1.145 \\
\hline Population county & $105,937(1,524,223)$ & $1,160-9,818,605$ & $0.00(0.00)$ & -0.03 & -1.495 \\
\hline Average travel time to work, min & $23(5.0)$ & $6-42.5$ & $-0.06(0.02)$ & -0.06 & -3.054 \\
\hline Non-English speaking, \% & $8.6 \%(15.1 \%)$ & $0.2 \%-95.9 \%$ & $-0.00(0.03)$ & -0.06 & -0.028 \\
\hline Total female, $\%$ & $50.7 \%(1.6 \%)$ & $34.4 \%-57.0 \%$ & $-0.23(0.07)$ & -0.06 & -3.158. \\
\hline Population $\geq 65$ years old, \% & $14.7 \%(4.1 \%)$ & $5.8 \%-49.3 \%$ & $-0.10(0.04)$ & -0.07 & -2.411 \\
\hline Population in poverty, $\%$ & $14.7 \%(5.6 \%)$ & $5.8 \%-49.3 \%$ & $-0.02(0.02)$ & -0.08 & -1.01 \\
\hline Population density & $138.7(4,534)$ & $0.3-69,467$ & $-0.24(0.09)$ & -0.08 & -2.823. \\
\hline Foreign born, $\%$ & $4.9 \%(9.3 \%)$ & $0 \%-51.2 \%$ & $-0.07(0.02)$ & -0.12 & $-4.906^{\star}$ \\
\hline Median household income & $\$ 46,880(\$ 12,868)$ & $\$ 20,206-\$ 120,096$ & $-0.00(0.00)$ & -0.16 & -2.599 \\
\hline No. of hospital beds & $103(193)$ & $2-2,259$ & $-0.00(0.00)$ & -0.16 & $-9.167^{\star}$ \\
\hline Model statistics & \multicolumn{5}{|c|}{$F(1,9)=62.222, P<0.001$} \\
\hline Adjusted $R^{2}$ & \multicolumn{5}{|c|}{0.124} \\
\hline
\end{tabular}

NOTE: This model demonstrates the multivariate association of 20 predictor variables with pain management patient satisfaction as determined by hospital percentage of patients who stated that their pain was "always" well controlled (median 71\%, SD 5.5, range 33\%-100\%). Abbreviations: HCAHPS = Hospital Consumer Assessment of Healthcare Providers and Systems; SD, standard deviation; SE, standard error. * $P<0.001$. ...P $<0.01$.

Bivariate analyses were conducted to determine which US Census categories were significant predictors for patient satisfaction with pain management. All significant predictors were then included in a multivariate model, which predicted for patient satisfaction with pain management. All analyses were 2-tailed, and statistical significance was set at $\alpha=0.05$.

\section{RESULTS}

Complete HCAHPS scores were obtained from 3907 hospitals out of a total of 4621 US hospitals (85\%). The majority of hospitals $(73.8 \%, \mathrm{n}=2884)$ collected over 300 surveys, fewer $(\mathrm{n}=696)$ collected 100 to 299 surveys, and a small number of hospitals $(\mathrm{n}=$ 327) collected less than 100 surveys. Based on the most conservative estimate, results were available from at least 934,800 individual surveys. Missing HCAHPS hospital data averaged 13.4 (standard deviation $[\mathrm{SD}]=12.2$ ) hospitals per state. County-level data were obtained from all 3144 county or county equivalents across the United States (100\%).

\section{Bivariate Analyses}

Univariate regression indicated a significant association between pain management patient satisfaction and most county-level demographic variables and number of hospital beds.

\section{Multivariate Analyses}

A multivariate linear regression model was run in which 20 county-level demographic and hospital factors were examined as predictors of patient satisfaction with pain management. The model, which examined county-level predictors of pain management, explained $12 \%$ of the variability in patients' ratings of pain management $\left(R^{2}=0.124, P<0.0001\right)$. A total of 8 out of the 20 US Census variables were statistically significant predictors of pain management (Table 2). African American and white race were most strongly associated with higher ratings of patient satisfaction with pain management (ie, by partial coefficient and statistical significance). Number of hospital beds, percent foreign born, population density, and female gender were most strongly related to lower ratings of patient satisfaction with pain management.

\section{DISCUSSION}

By utilizing county-level demographic data and the HCAHPS survey measures from across the United States, this study provides a representative sample of US hospitals that can be used to define ecological trends in patient satisfaction with pain management. This statistical model demonstrates the nonrandom variability of pain management satisfaction across the United States, even after CMS patient-mix adjustment. Although the quality of pain management may be increasing by some reports, our present results indicate that pain management satisfaction is not equitable with the rest of the country among select groups of patients (eg, foreign born, female gender, areas of long travel times to work) or in certain care settings (eg, larger 
hospitals, population dense areas). These data suggest that areas of pain management may lack in quality compared to pain management across the entire US as a whole. This is consistent with the increasingly recognized contribution of multiple nonmedical determinates to health outcomes. ${ }^{12}$ These results demonstrate the overall magnitude of healthcare disparity in the United States, and are particularly concerning because African Americans and Hispanics tend to rate overall satisfaction higher than Caucasians in other studies. ${ }^{13,14}$ The same minority reporting bias may be reflected in HCAHPS results. These patients may be reporting higher pain management satisfaction that is not consistent with the level of care they received, as studies have consistently indicated worse pain management delivery for racial and ethnic minorities. ${ }^{15}$

The present findings reveal structural (eg, hospital beds) and demographic (eg, population density, foreign born) gaps in satisfaction with pain management. An effort to improve pain management for all people in the heterogeneous makeup of the United States is an enormous challenge. However, change may be forthcoming, as Hospital Value-Based Purchasing draws attention pain practice inequities in real time. Although several of the significant explanatory variables cannot be modified (eg, size of hospital, urban setting, patients served), pain management delivery should receive extra attention in hospitals with those characteristics. Pain management delivery in large, urban hospitals that serve foreign-born patients may be improved with focused multilevel interventions. Future research should examine these inequities further and develop multilevel interventions that target hospitals in at-risk areas with the aim of lessening disparities in hospital-based pain management.
Disclosure: Nothing to report.

\section{References}

1. Dwamena F, Holmes-Rovner M, Gaulden CM, et al. Interventions for providers to promote a patient-centred approach in clinical consultations. Cochrane Database Syst Rev. 2012;12:CD003267.

2. Gupta A, Daigle S, Mojica J, Hurley RW. Patient perception of pain care in hospitals in the United States. J Pain Res. 2009;2:157-164.

3. Gupta A, Lee LK, Mojica JJ, Nairizi A, George SJ. Patient perception of pain care in the United States: a 5-year comparative analysis of hospital consumer assessment of health care providers and systems. Pain Physician. 2014;17(5):369-377.

4. Phillips S, Gift M, Gelot S, Duong M, Tapp H. Assessing the relationship between the level of pain control and patient satisfaction. J Pain Res. 2013;6:683-689.

5. H.R.3590-Patient Protection and Affordable Care Act 2010. Available at: https://www.congress.gov/bill/111th-congress/house-bill/ 3590. Accessed December 1, 2013.

6. Centers for Medicare \& Medicaid Services. Official hospital compare data. Available at: http://data.medicare.gov/data/hospital-compare/ PatientSurveyResults. Accessed December 1, 2013.

7. Macintyre S, Ellaway A, Cummins S. Place effects on health: how can we conceptualise, operationalise and measure them? Soc Sci Med. 2002;55(1):125-139.

8. Joynt KE, Jha AK. Characteristics of hospitals receiving penalties under the Hospital Readmissions Reduction Program. JAMA. 2013; 309(4):342-343.

9. Jha AK, Orav EJ, Zheng J, Epstein AM. Patients' perception of hospital care in the United States. N Engl J Med. 2008;359(18):1921-1931.

10. American Hospital Directory. Hospital statistics by state. Available at: http://www.ahd.com/state_statistics.html. Accessed December 1, 2013.

11. United States Census Bureau. Download center. Available at: http:// factfinder.census.gov/faces/nav/jsf/pages/download_center.xhtml. Accessed December 1, 2013.

12. Health policy brief: the relative contribution of multiple determinants to health outcomes. Health Affairs website. Available at: http://www. healthaffairs.org/healthpolicybriefs/brief.php?brief_id=123. Accessed December 1, 2013.

13. Dayton E, Zhan C, Sangl J, Darby C, Moy E. Racial and ethnic differences in patient assessments of interactions with providers: disparities or measurement biases? Am J Med Qual. 2006;21(2): 109-114.

14. Weech-Maldonado R, Elliott MN, Oluwole A, Schiller KC, Hays RD. Survey response style and differential use of CAHPS rating scales by Hispanics. Med Care. 2008;46(9):963-968.

15. Institute of Medicine. Committee on Advancing Pain Research, Care, and Education. Relieving Pain in America: A Blueprint for Transforming Prevention, Care, Education, and Research. Washington, DC: National Academies Press; 2011. 